\title{
EDITORIAL
}

\section{Cystic fibrosis and bone disease: are we missing a genetic link?}

\author{
R.M. Aris* and T.A. Guise"
}

The manuscript by KING et al. [1] in this issue of the European Respiratory Journal raises the possibility that mutations in the cystic fibrosis (CF) transmembrane conductance regulator (CFTR) may be responsible, at least in part, for low bone density in CF cohorts. More than 100 publications from around the globe, the majority in the last decade, have described low bone density in CF adult and, to a lesser extent, paediatric populations. The pathogenesis, epidemiology, clinical manifestations, and preventative and therapeutic options have all been discussed previously [2]. While the primary clinical correlates of low bone density in CF have previously been measures of lung function, body mass index and corticosteroid use [2], the good work of KING et al. [1] has, for the first time, reported a direct link with $\Delta \mathrm{F} 508$ (the major disease-causing mutation of the CFTR consisting of deletion of phenylalanine 508). While others have looked for this association in the past without success [3-5], the work of KING et al. [1] does raise some very interesting possibilities.

The fundamental question is: do mutations in CFTR cause low bone density and, if so, what are the mechanisms (via direct channel functions, interaction with other ion channels or other means). This editorial will concentrate almost exclusively on this topic, since other aspects of CF bone disease have been explored in detail elsewhere. The most likely, albeit not the only, link between bone health and CFTR may be found in the gut, kidney, parathyroid glands or bone. A discussion about the well-known effects of pancreatic insufficiency on fatsoluble vitamin absorption and their role in bone mineralisation is excluded here. The most important issue is whether chloride channels, which are numerous in type and expressed almost ubiquitously in all tissues types, are linked to a pathophysiological alteration that causes reduced bone density and if the CFTR is causally involved in this process (rather than a different chloride ion $\left(\mathrm{Cl}^{-}\right)$channel).

CFTR is expressed in the epithelia of the intestinal tract, and mutations are thought to underlie disorders such as distal intestinal obstruction syndrome [6]. $\mathrm{Cl}^{-}$transport may affect the transport of other ions, such as calcium ions $\left(\mathrm{Ca}^{2+}\right)$, directly or indirectly, although the mechanisms are unknown. $\mathrm{Ca}^{2+}$ absorption may be reduced in CF [7], but this finding is not

${ }^{*}$ University of North Carolina, Chapel Hill, NC, and "the University of Virginia, Charlottesville, VA, USA.

Correspondence: R.M. Aris, University of North Carolina, Chapel Hill, NC, USA. E-mail: robert_aris@med.unc.edu without controversy. $\mathrm{Ca}^{2+}$ intestinal losses may also be high in $\mathrm{CF}$, due to excessive secretion of $\mathrm{Ca}^{2+}$ into the lumen of the gastrointestinal (GI) tract [8]. Intestinal permeability is four- to 10-times greater in patients with CF than in healthy controls [9] and this increased permeability is thought to occur through compromised tight junctions in a paracellular manner. Increased intestinal permeability in CF may be a primary consequence of the genetic defect, as the degree of intestinal permeability has been linked to the $\Delta$ F508 genotype. Thus, poor $\mathrm{Ca}^{2+}$ absorption and excessive $\mathrm{Ca}^{2+}$ secretion in the GI tract may ultimately contribute to bone disease.

The kidneys play a major role in the integrated regulation of $\mathrm{Ca}^{2+}$ and phosphorus (P) homeostasis. Although CFTR is expressed in various nephron segments, there is no overt renal phenotype in $\mathrm{CF}$ and no studies indicating its role in the regulation of other ion channels [10]. Renal $\mathrm{Ca}^{2+}$ absorption across polarised epithelial cells is a two-step process. $\mathrm{Ca}^{2+}$ entry across apical membranes is followed by extrusion across basolateral membranes into interstitial fluid and, hence, into the circulation. Adequate supplies of inorganic $\mathrm{P}(\mathrm{Pi})$, derived from plasma, are a prerequisite for normal cell and body functions, such as bone growth and remodelling. Renal regulation of $\mathrm{Pi}$ absorption is a major determinant of extracellular $\mathrm{P}$ homeostasis. Three sodium ion $\left(\mathrm{Na}^{+}\right)-\mathrm{Pi}$ cotransporters have been identified [11]. The type IIa $\mathrm{Na}^{+}-\mathrm{Pi}$ cotransporter accounts for $\sim 70 \%$ of brush-border membrane $\mathrm{P}$ uptake activity and is the target of the parathyroid hormone (PTH). Apical Pi uptake is coupled to $\mathrm{Na}^{+}$, which enters the cell down its electrochemical gradient. $\mathrm{Ca}^{2+}$-sensing receptors (CaSR) play a role in $\mathrm{Ca}^{2+}$ homeostasis independently of $\mathrm{PTH}$ by regulating $\mathrm{Ca}^{2+}$ retrieval from the tubules. It remains to be determined, however, whether CaSR and the $\mathrm{Na}^{+}-\mathrm{Pi}$ cotransporter are actually colocalised and whether the former regulates the activity of the latter. The conserved C-terminal peptide motif (1476DTRL) of CFTR ensures high affinity binding to different PDZ domaincontaining molecules, including the $\mathrm{Na}^{+} /$hydrogen exchanger regulatory factor and the bicarbonate $\left(\mathrm{HCO}_{3}^{-}\right)$salvage transporter human $\mathrm{Na}^{+}-\mathrm{HCO}_{3}{ }^{-}$cotransport isoform 3 in other epithelial tissues, including the airway [12]. The main area of speculation with regard to bone disease is whether this C-terminal motif on CFTR can interact with other renal transporter proteins that may affect $\mathrm{Na}^{+}, \mathrm{P}$ or $\mathrm{Ca}^{2+}$ handling and, ultimately, impact bone mineralisation. To the best of our knowledge, this putative interaction has not been investigated. 
PTH secretion by the parathyroid gland is the principal mechanism used to maintain $\mathrm{Ca}^{2+}$ homeostasis. Parathyroid function is critical to bone health because the skeleton serves as the largest reservoir of $\mathrm{Ca}^{2+}$ in the body and it is actively reabsorbed to keep serum $\mathrm{Ca}^{2+}$ levels in a very narrow range. Parathyroid cells are epithelial cells with the capacity to directly sense and be regulated by changes in extracellular $\mathrm{Ca}^{2+}$ through a receptor-mediated mechanism [13]. The secretory apparatus of parathyroid cells is inversely regulated by acute elevations of $\mathrm{Ca}^{2+}$, a process mediated by the CaSR. Parathyroid chief cells are polarised in intact glands with an apico-lateral localisation of CaSRs. The CaSRs colocalise with ATPase, alkaline phosphatase, 5'-nucleotidase and other signalling proteins, including $\mathrm{Gq} / 11$, endothelial nitric oxide synthase and several protein kinase $\mathrm{C}(\mathrm{PKC})$ isoforms (i.e. $\alpha, \delta$, and $\zeta$ ) [13]. To the best of our knowledge, nothing is known about the expression of CFTR in parathyroid epithelial tissues. It is provocative that PKC activity, which is known to regulate CFTR [14], is also important in CaSR signal transduction, as it pertains to $\mathrm{Ca}^{2+}$ homeostasis. Whether CFTR is expressed in the parathyroid gland and plays a functional role in $\mathrm{Ca}^{2+}$ homeostasis is unknown but has been hypothesised on the basis of animal work with the CFTR-null mouse [15].

Perhaps, intuitively, the most likely genetic link between mutant CFTR and bone disease can be found in bone physiology. Unfortunately, little is known about whether CFTR is expressed or functional in bone tissue. The same paradigm discussed above pertains to bone tissue, namely attempting to find a link between the channel or regulatory functions of CFTR and those of other ion channels (e.g. $\mathrm{Ca}^{2+}, \mathrm{P}$ and magnesium) that are involved in bone formation or matrix mineralisation. Bone formation is significantly reduced in adults with CF, using the tetracycline double-label, goldstandard method applied to bone histomorphometry [16]. Skeletal retention of $\mathrm{Ca}^{2+}$ is also low in young girls with $\mathrm{CF}$, again suggesting a defect in bone formation [17]. In addition, both cortical and trabecular bone formation (using doublelabelling methods) is significantly reduced in the CF "knockout" $^{\prime \prime}$ mouse [15]. Fortunately, for the study of bone disease in this mouse model of $\mathrm{CF}$, the shortened life span of the animal is due primarily to complications arising from obstruction of the intestinal tract, rather than lung infection. Thus, in contrast to human patients, CF mice do not require pharmacological treatment (e.g. antibiotics and glucocorticoids), and the impact of these confounders on bone biology is almost eliminated.

The most likely candidate for mutant CFTR-associated dysfunction in bone is the osteoblast, the bone cell responsible for bone formation. Osteoblasts are normally arranged as cuboidal or low columnar epithelial cells during active bone formation in vivo. They are actively polarised in a manner that makes them appear as though they are standing on their heads on bone surfaces (apical membrane pointing toward bone). Like epithelial cells, they exhibit polarised secretory properties. Osteoblasts express at least three families of $\mathrm{Cl}^{-}$channels, including $\mathrm{Na}^{+}-\mathrm{Cl}^{-}$cotransporters, potassium $(\mathrm{K})-\mathrm{Cl}^{-}$cotransporters and $\mathrm{Na}^{+}-\mathrm{K}^{+}-2 \mathrm{Cl}^{-}$cotransporters [18]. Activation of the osteoblast can be achieved through cotransporter functions. In one study, performed before CFTR was sequenced, CHESNOYMARCHAIS and FRITSCH [19] reported that cyclic AMP sensitivity, outward rectification and the sensitivity to dialysis of the (rat) osteoblast $\mathrm{Cl}^{-}$current were reminiscent of the properties of the CF-sensitive $\mathrm{Cl}^{-}$channels of epithelial cells.

Osteoclasts or bone-resorbing cells, unlike osteoblasts, are phagocytes functionally and morphologically, but are also rich in ion channels. Excessive bone resorption has been found in CF human and animal studies, but the animal data suggest that cortical bone is more involved than trabecular bone [15, 20, 21] In order to solubilise bone mineral and degrade the organic matrix of bone, osteoclasts secrete $1-2 \mathrm{H}^{+}$for every $\mathrm{Ca}^{2+}$ liberated. This transport is a major metabolic activity of osteoclasts, requiring a $\mathrm{H}^{+}$-ATPase, $\mathrm{Cl}^{-}$channel, a $\mathrm{Cl}^{-}-\mathrm{HCO}^{-}$ exchanger, carbonic anhydrase and a morphological polarisation of the cell [22]. The osteoclast $\mathrm{H}^{+}$-ATPase is electrically coupled to a $\mathrm{Cl}^{-}$channel in the ruffled membrane. The carbonic anhydrase and $\mathrm{Cl}^{-}-\mathrm{HCO}^{-}$exchange provide an interface with $\mathrm{pH}$ regulation and integrate bone resorption into systemic acid-base balance. The expression and/or function of CFTR in osteoclasts are unknown.

Skeletal strength is dependent on the tightly coupled and coordinated activity between osteoclastic bone resorption and osteoblastic bone formation. Thus, it will be crucial to determine the following: 1) if CFTR is expressed in osteoblasts and osteoclasts; 2 ) its functional role in the biological effects of these bone cells; and 3) if the $\Delta \mathrm{F} 508$ mutation alters the biological effects. The interaction between the possible direct role of CTFR in bone cell function and $\mathrm{Ca}^{2+}$ homeostasis, and the known indirect effects of $\mathrm{CF}$ on $\mathrm{Ca}^{2+}$ and bone metabolism are probably complex and will require further investigation.

In conclusion, since cystic fibrosis has many systemic manifestations, a better understanding of the basic gene defect in a variety of tissue types beyond the lung, gut, sweat glands and biliary tree may further enhance our understanding of this disorder. The article by KING et al. [3] in this issue of the European Respiratory Journal certainly raises our awareness that low bone density creates a proclivity for fractures and kyphosis in cystic fibrosis, and tantalises us with the possibility that it is linked to mutations in cystic fibrosis transmembrane conductance regulator. Hopefully, science will soon provide an answer.

\section{REFERENCES}

1 King SJ, Topliss DJ, Kotsimbos $\mathrm{T}$, et al. Reduced bone density in cystic fibrosis: $\Delta \mathrm{F} 508$ mutation is an independent risk factor. Eur Respir J 2004; 25: 54-61.

2 Aris RM, Lester GE, Ontjes DA. Treatment of bone disease in cystic fibrosis. Curr Opin in Pulm Med 2005 (in press).

3 Aris RM, Renner JB, Winders AD, et al. Increased fractures and severe kyphosis: sequelae of living into adulthood with cystic fibrosis. Ann Int Med 1998; 128: 186-193.

4 Haworth CS, Selby PL, Webb AK, et al. Low bone mineral density in adults with cystic fibrosis. Thorax 1999; 54: 961-967.

5 Buntain HM, Greer RM, Schluter PJ, et al. Bone mineral density in Australian children, adolescents and adults with cystic fibrosis: a controlled cross sectional study. Thorax 2004; 59: 149-155.

6 Berschneider HM, Knowles MR, Azizkham RG, et al. Altered intestinal chloride transport in cystic fibrosis. FASEB J 1988; 2: 2625-2629. 
7 Aris RM, Lester G, Dingman S, Ontjes DA. Altered calcium homeostasis in adults with cystic fibrosis. Osteoporos Int 1999; 10: 102-108.

8 Schulze KJ, O’Brien KO, Germain-Lee EL, Baer DJ, Leonard AL, Rosenstein BJ. Endogenous fecal losses of calcium compromise calcium balance in pancreaticinsufficient girls with cystic fibrosis. J Pediatr 2003; 143: 765-771.

9 Gregory PC. Gastrointestinal pH, motility/transit and permeability in cystic fibrosis. J Pediatr Gastroenterol Nutr 1996; 23: 513-523.

10 Devuyst O, Guggino WB. Chloride channels in the kidney: lessons learned from knockout animals. Am J Physiol Renal Physiol 2002; 283: F1176-F1179.

11 Ba J, Friedman PA. Calcium-sensing receptor regulation of renal mineral ion transport. Cell Calcium 2004; 35: 229-237.

12 Park M, Ko SB, Choi JY, et al. The cystic fibrosis transmembrane conductance regulator interacts with and regulates the activity of the $\mathrm{HCO} 3$ - salvage transporter human Na+-HCO3- cotransport isoform 3. J Biol Chem 2002; 277: 50503-50509.

13 Chen RA, Goodman WG. Role of the calcium-sensing receptor in parathyroid gland physiology. Am J Physiol Renal Physiol 2004; 286: F1005-F1011.

14 Chappe V, Hinkson DA, Howell LD, et al. Stimulatory and inhibitory protein kinase $C$ consensus sequences regulate the cystic fibrosis transmembrane conductance regulator. Proc Natl Acad Sci USA 2004; 101: 390-395.
15 Dif F, Marty C, Baudoin C, De Vernejoul MC, Levi G. Severe osteopenia in CFTR-null mice. Bone 2004; 35: 595-603.

16 Elkin SL, Vedi S, Bord S, Garrahan NJ, Hodson ME, Compston JE. Histomorphometric analysis of bone biopsies from the iliac crest of adults with cystic fibrosis. Am J Respir Crit Care Med 2002; 166: 1470-1474.

17 Schulze KJ, O'Brien KO, Germain-Lee EL, Booth SL, Leonard A, Rosenstein BJ. Calcium kinetics are altered in clinically stable girls with cystic fibrosis. J Clin Endocrinol Metab 2004; 89: 3385-3391.

18 Brauer M, Frei E, Claes L, Grissmer S, Jager H. Influence of $\mathrm{K}-\mathrm{Cl}$ cotransporter activity on activation of volumesensitive Cl- channels in human osteoblasts. Am J Physiol Cell Physiol 2003; 285: C22-C30.

19 Chesnoy-Marchais D, Fritsch J. Chloride current activated by cyclic AMP and parathyroid hormone in rat osteoblasts. Pflugers Arch 1989; 415: 104-114.

20 Baroncelli GI, De Luca F, Magazzu G, et al. Bone demineralization in cystic fibrosis: evidence of imbalance between bone formation and degradation. Pediatr Res 1997; 41: 397-403.

21 Aris RM, Ontjes DA, Buell HE, et al. Abnormal bone turnover in cystic fibrosis adults. Osteoporosis Int 2002; 13 : 151-157.

22 Schlesinger PH, Mattsson JP, Blair HC. Osteoclastic acid transport: mechanism and implications for physiological and pharmacological regulation. Miner Electrolyte Metab 1994; 20: 31-39. 